\title{
The SPARC water vapour assessment II: comparison of annual, semi-annual and quasi-biennial variations in stratospheric and lower mesospheric water vapour observed from satellites
}

Stefan Lossow et al.

Correspondence to: Stefan Lossow (stefan.lossow@kit.edu)

The copyright of individual parts of the supplement might differ from the CC-BY 3.0 licence. 
In the main manuscript we have shown in Figs. 1, 6 and 11 examples of the latitudealtitude distribution of amplitude and phase for the different variability patterns that are the focus of this work. For the sake of completeness we show here these distributions for all data sets. Figure 1 provides the overview for the annual variation, Fig. 2 focuses on the semi-annual variation and Fig. 3 correspondingly on the QBO variation. All figures extend over multiple pages to fit the panels for all data sets. For the annual and semiannual variation all 30 data sets that are part of the this study are shown. For the QBO variation in total 26 data sets are included, lacking the MIPAS V5H NOM data sets which cover only a period of 21 months. The key features for the different variability patterns described in the main manuscript (see Sects. 4.1.1, 4.2.1 and 4.3.1) are well depicted in many data sets. The MIPAS and MLS data sets provide results over almost the entire latitude-altitude domain considered in this work. Hence all the features can be addressed. Also the HALOE, SAGE II and SMR $489 \mathrm{GHz}$ data sets cover large parts of the domain. The remaining data sets provide a spatial snapshot covering some of the key features, but not in all cases. Figure 1 provides a good first overview of the spatial coverage of the individual data sets. It also shows those outliers in the variability amplitudes which we screened to provide reasonable estimates of the uncertainties of the variability characteristics (see Sect. 3.3). 

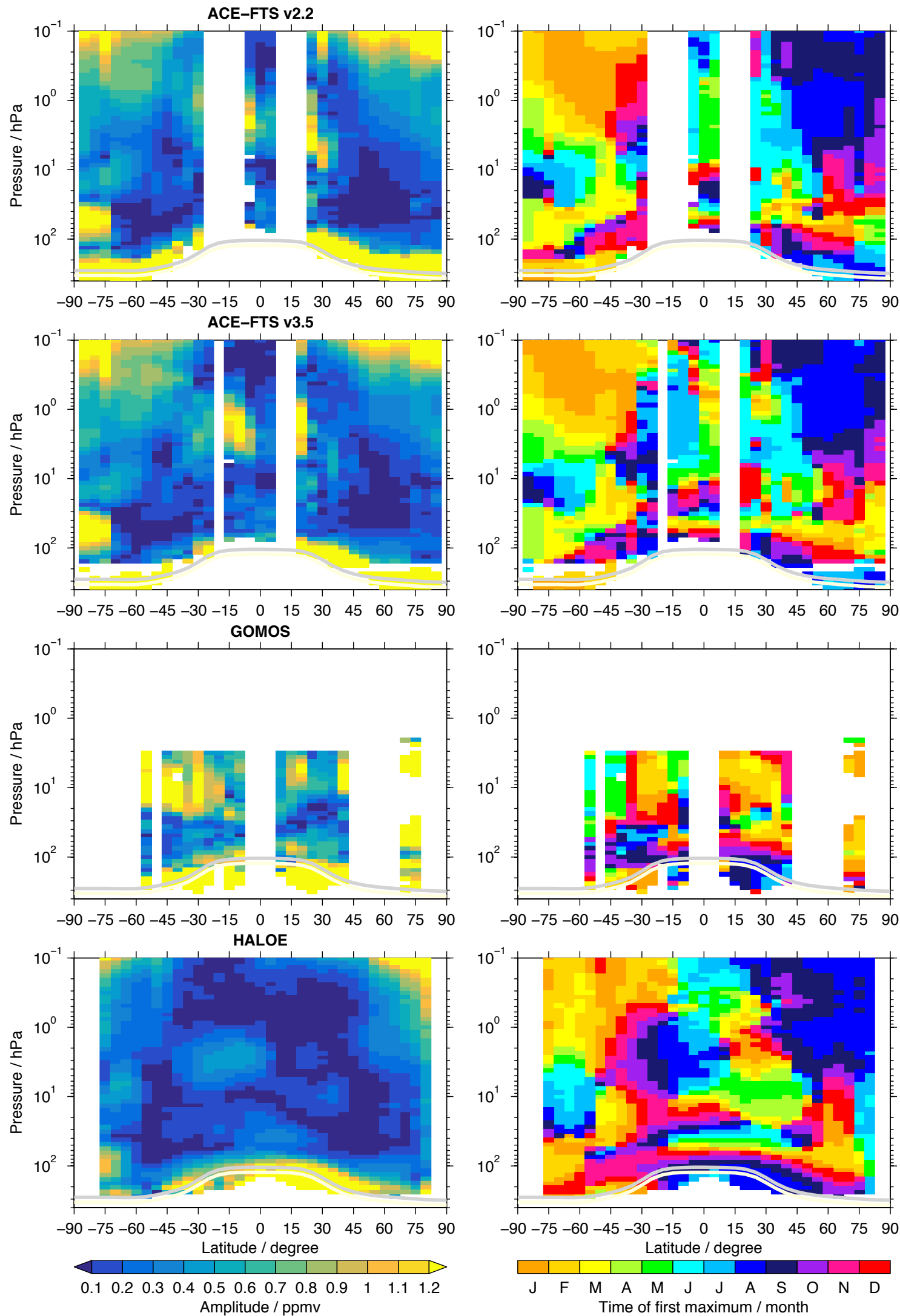

Continued on next page 

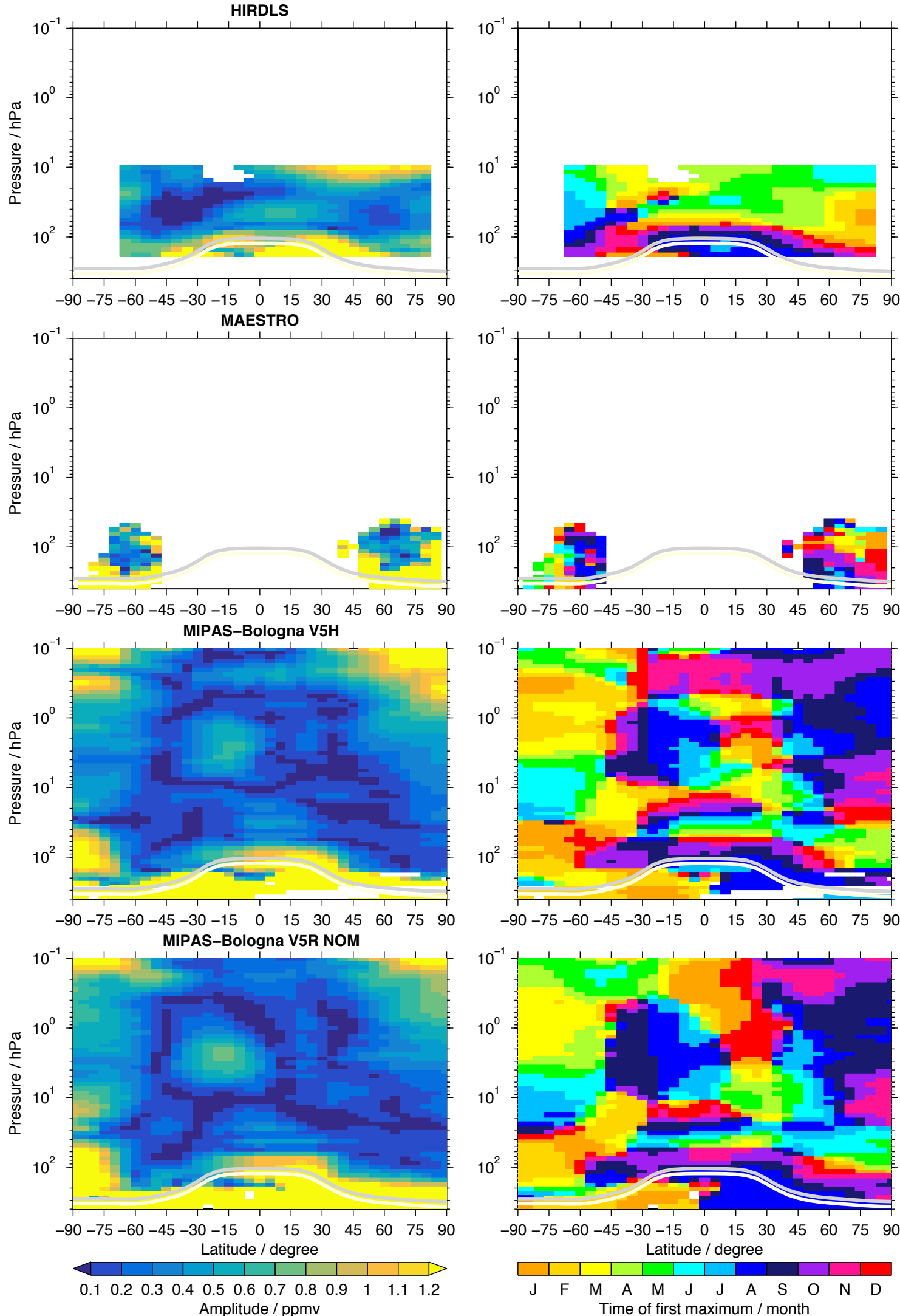

Continued on next page 

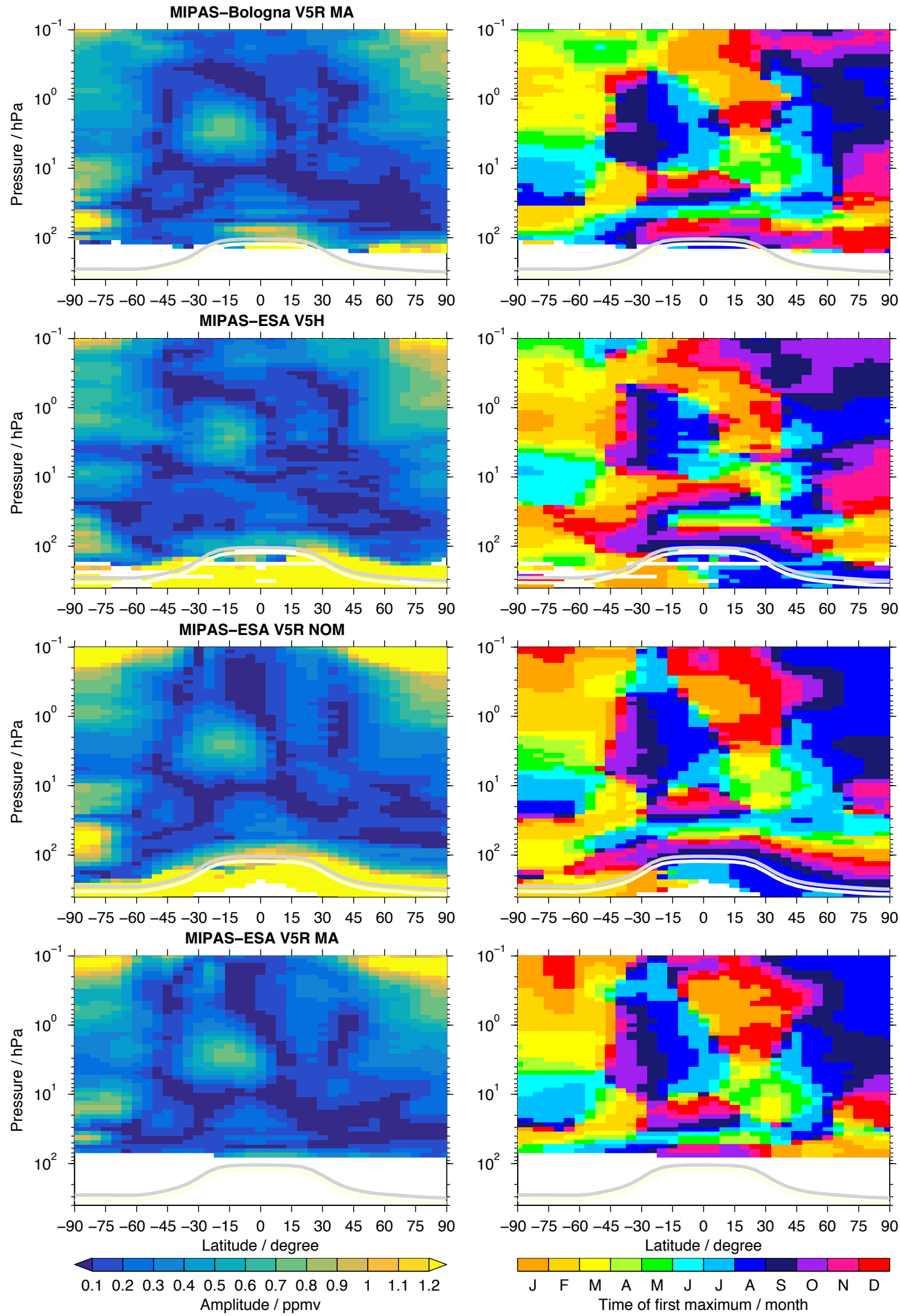

Continued on next page 

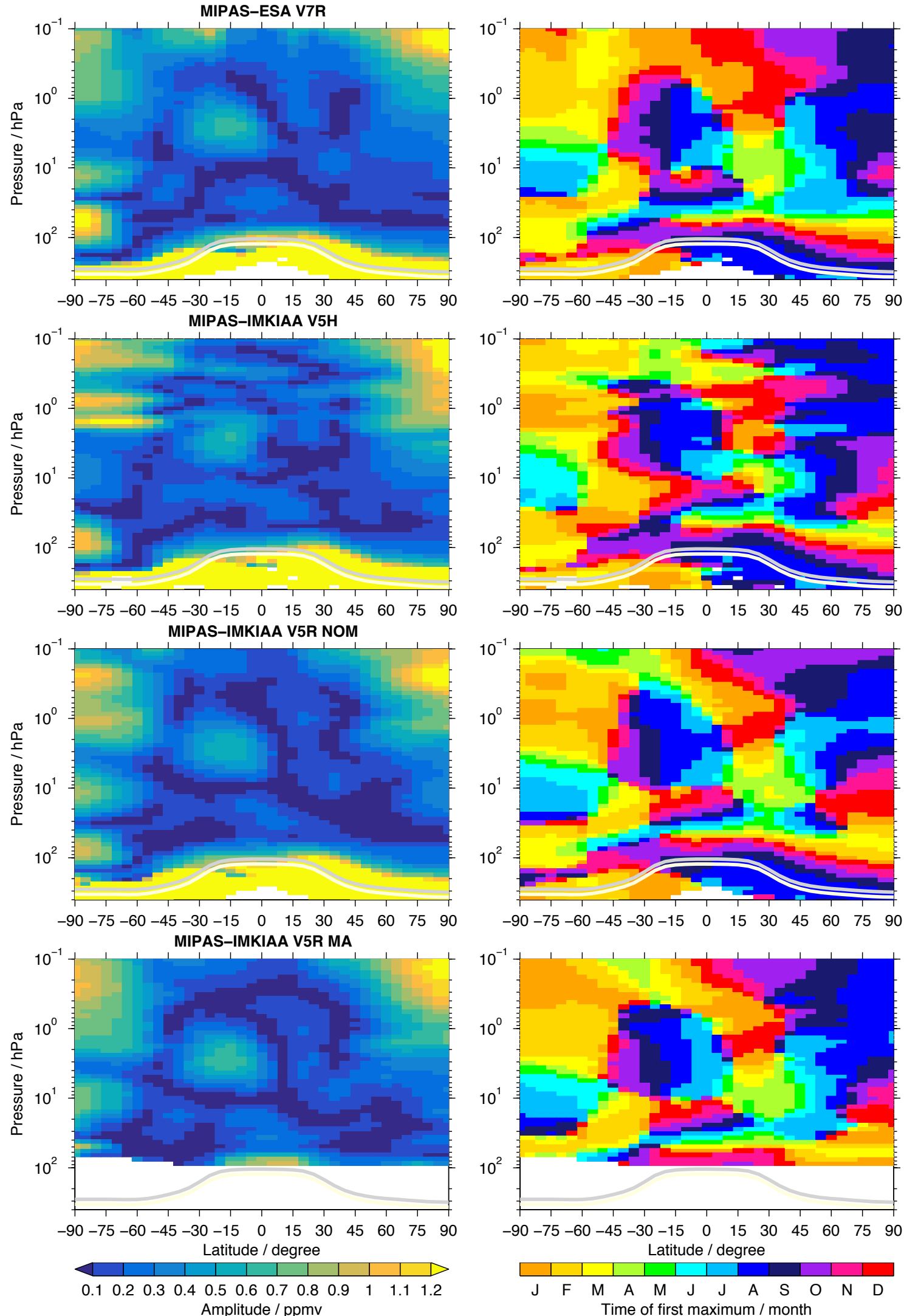

Continued on next page 

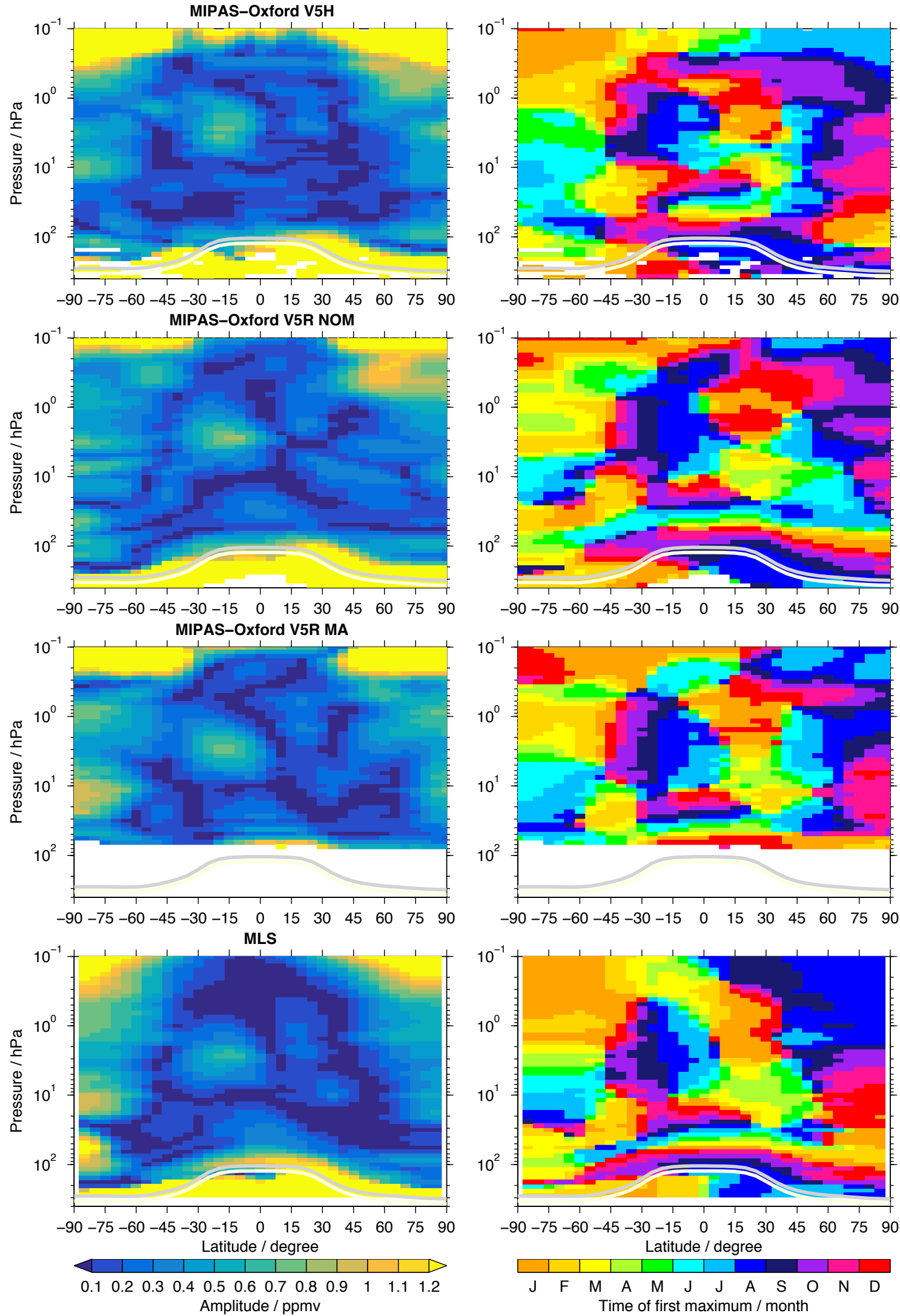

Continued on next page 

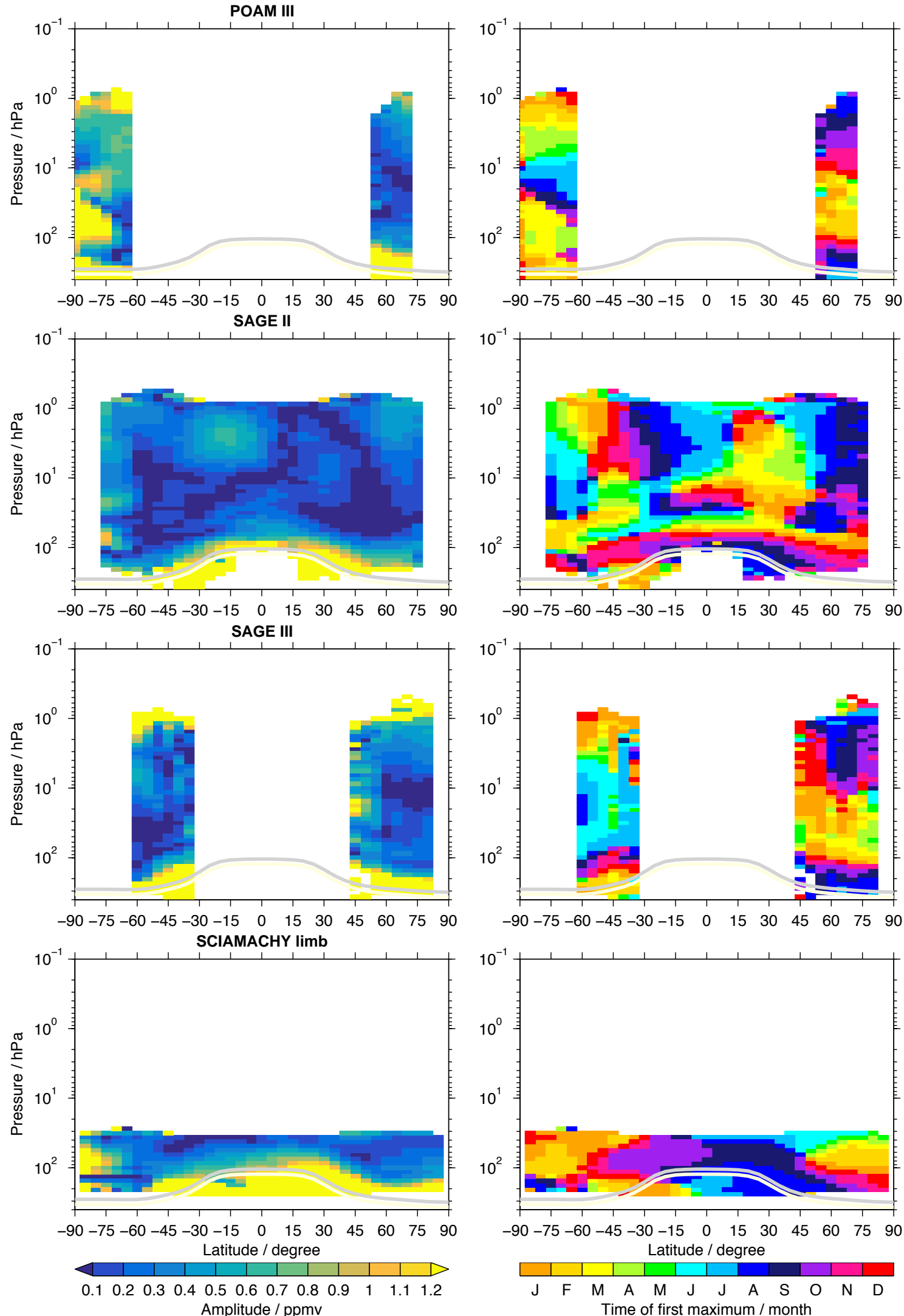

Continued on next page 

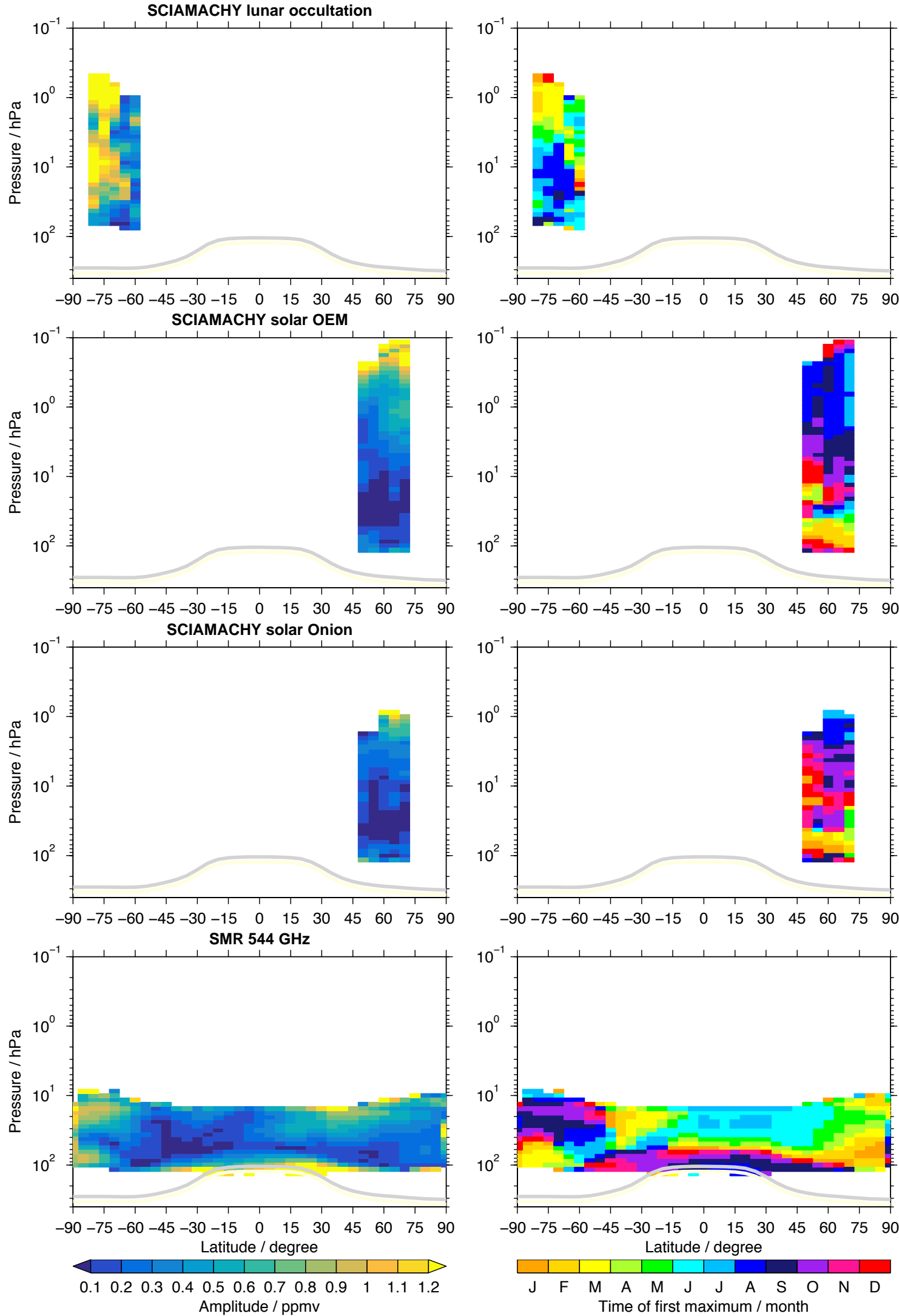

Continued on next page 

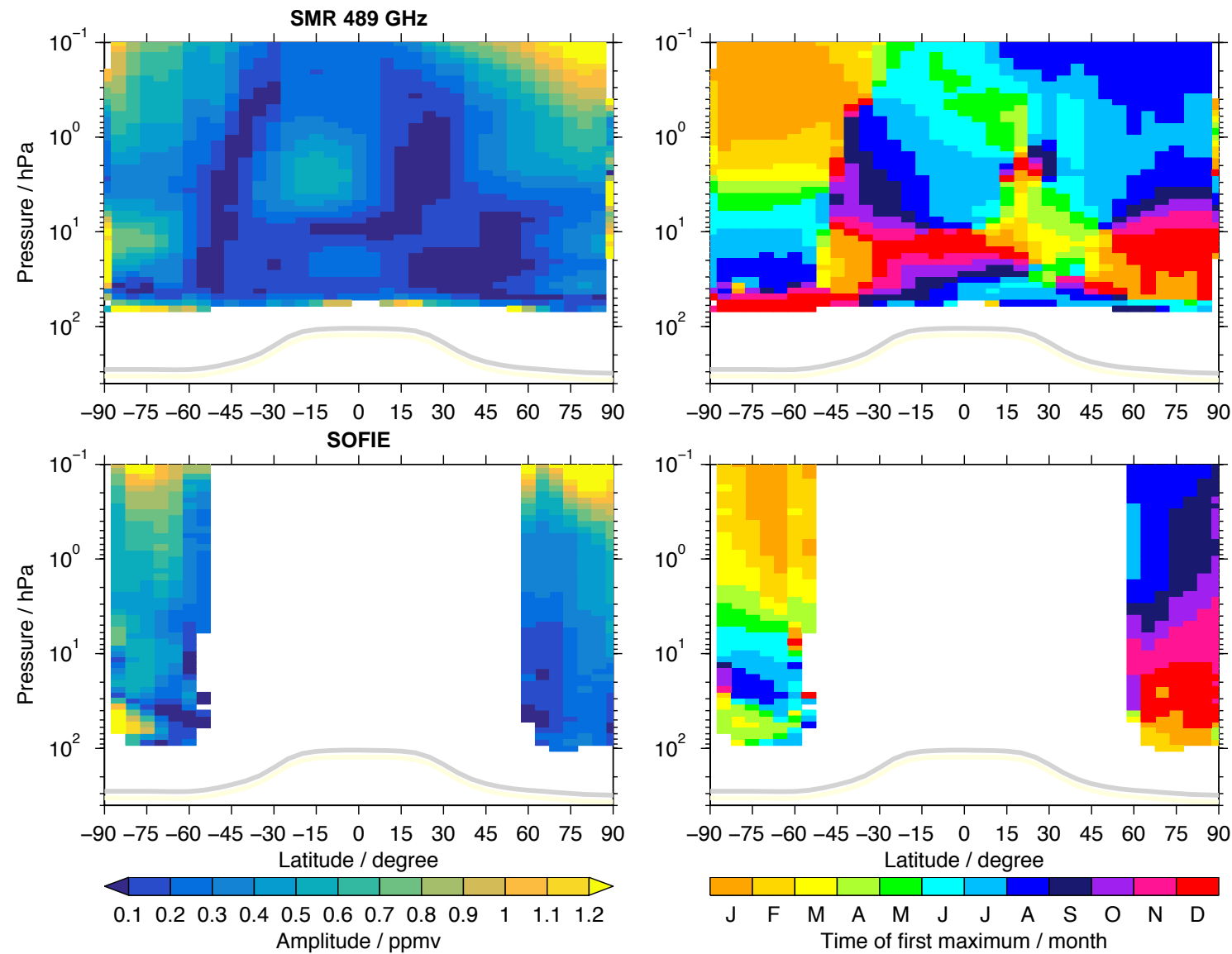

Figure 1: Latitude-altitude cross sections of amplitude (left panels) and phase (right panels) of the annual variation in water vapour for the satellite data sets considered in this analysis. The phase is given by the month in which water vapour exhibits its annual maximum in the regression fit. The light grey and white line indicates the mean tropopause $(2000-2014)$ as derived from the MERRA reanalysis data. White boxes indicate that there are no data. 

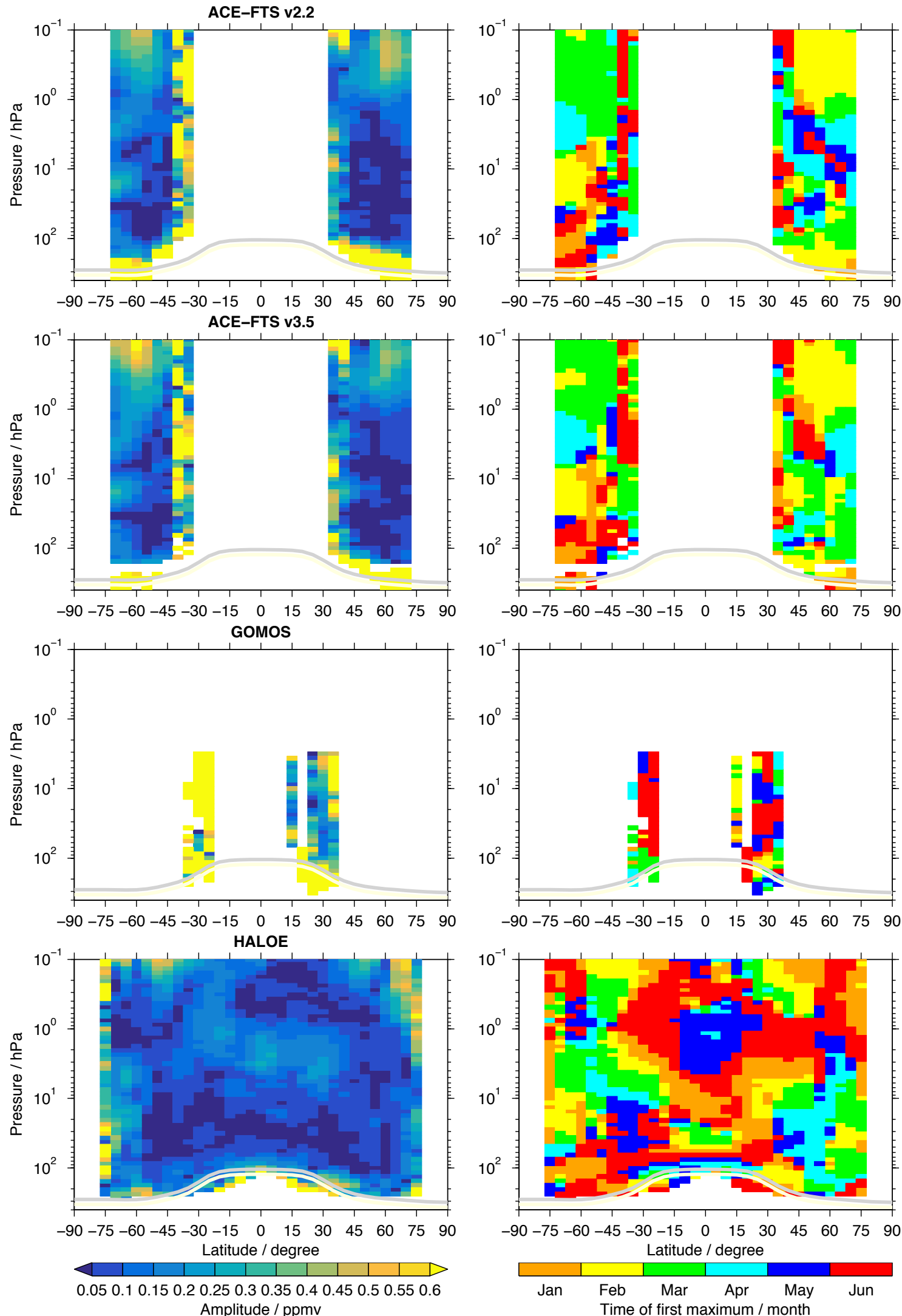

Continued on next page 

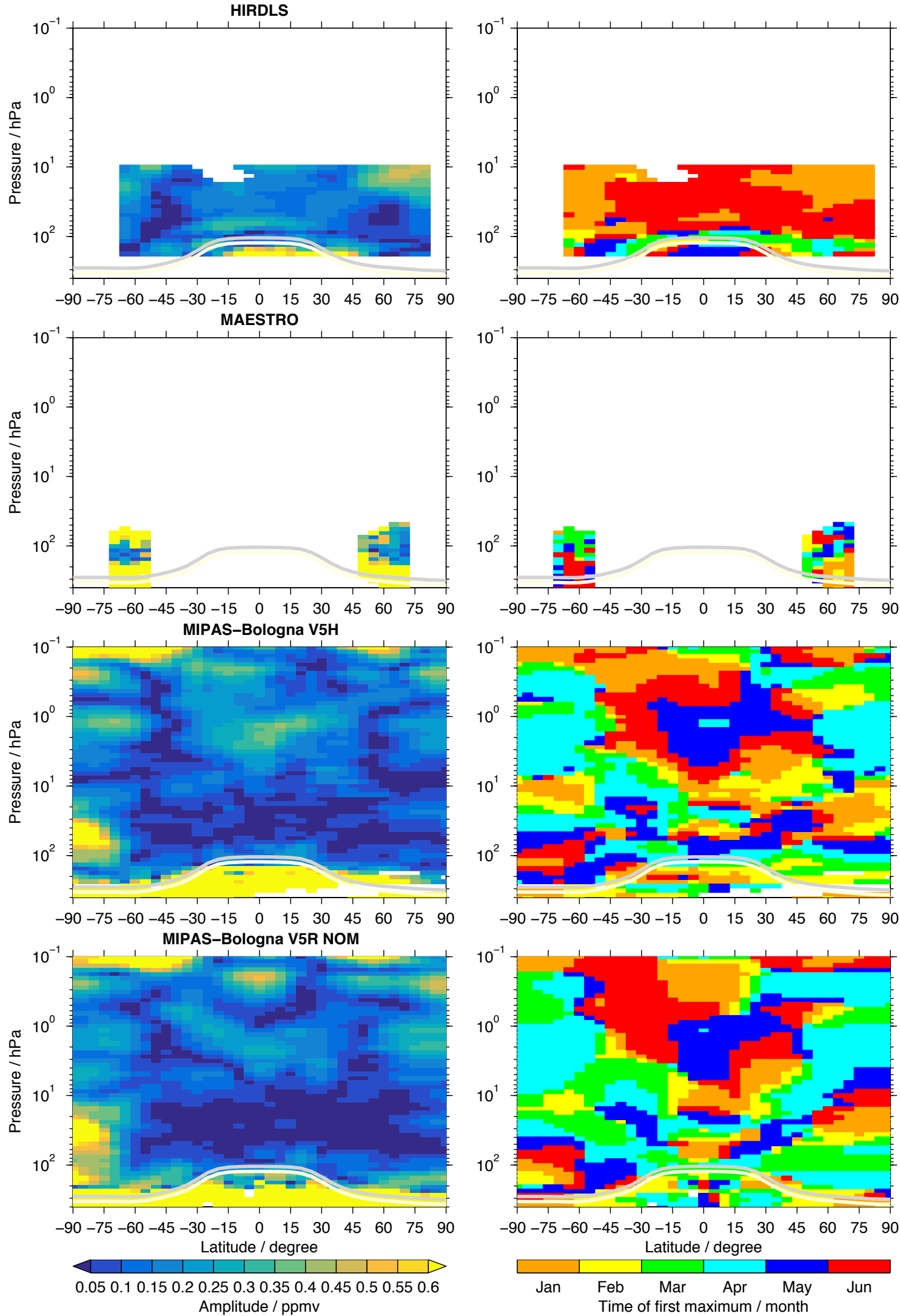

Continued on next page 

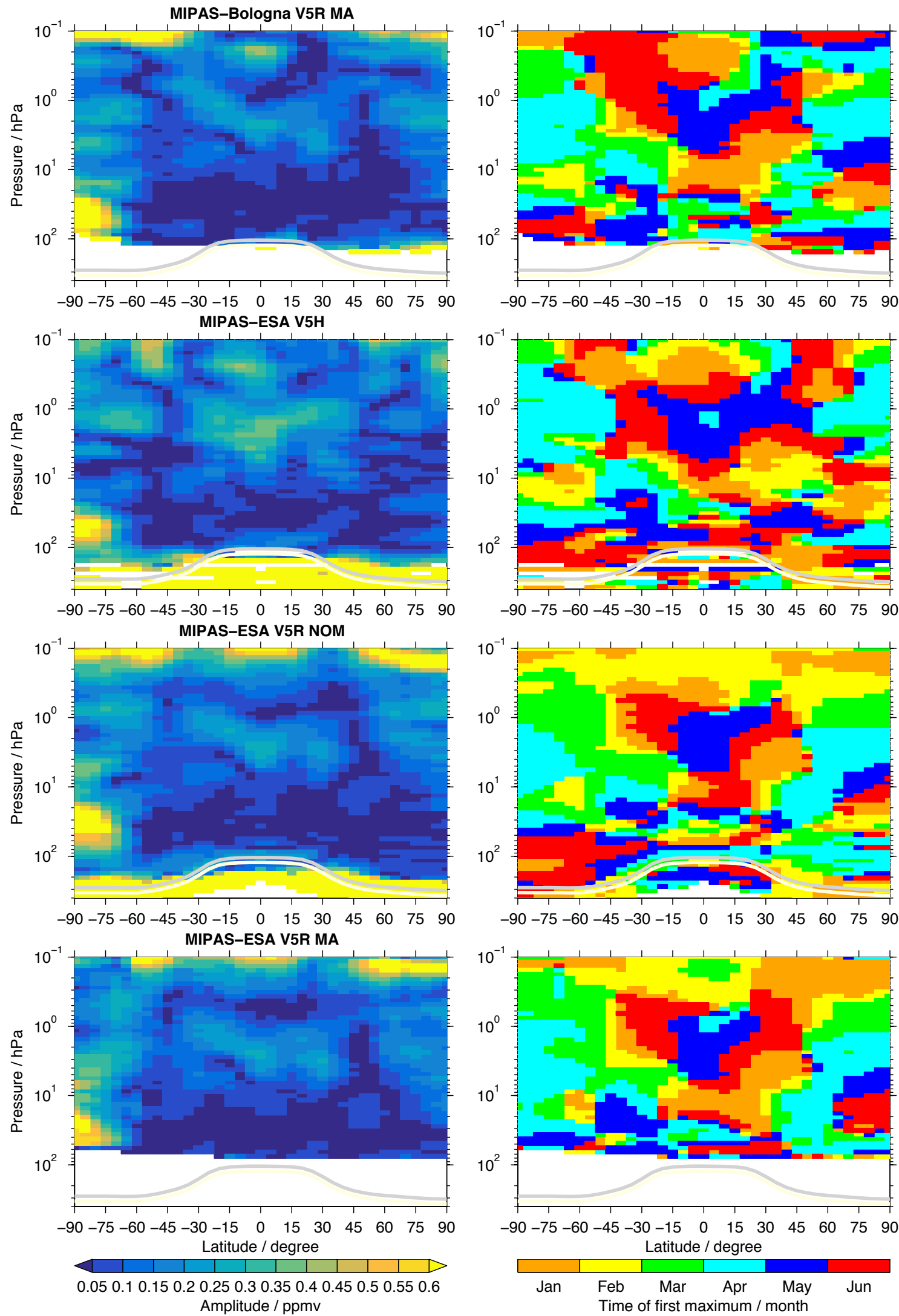

Continued on next page 

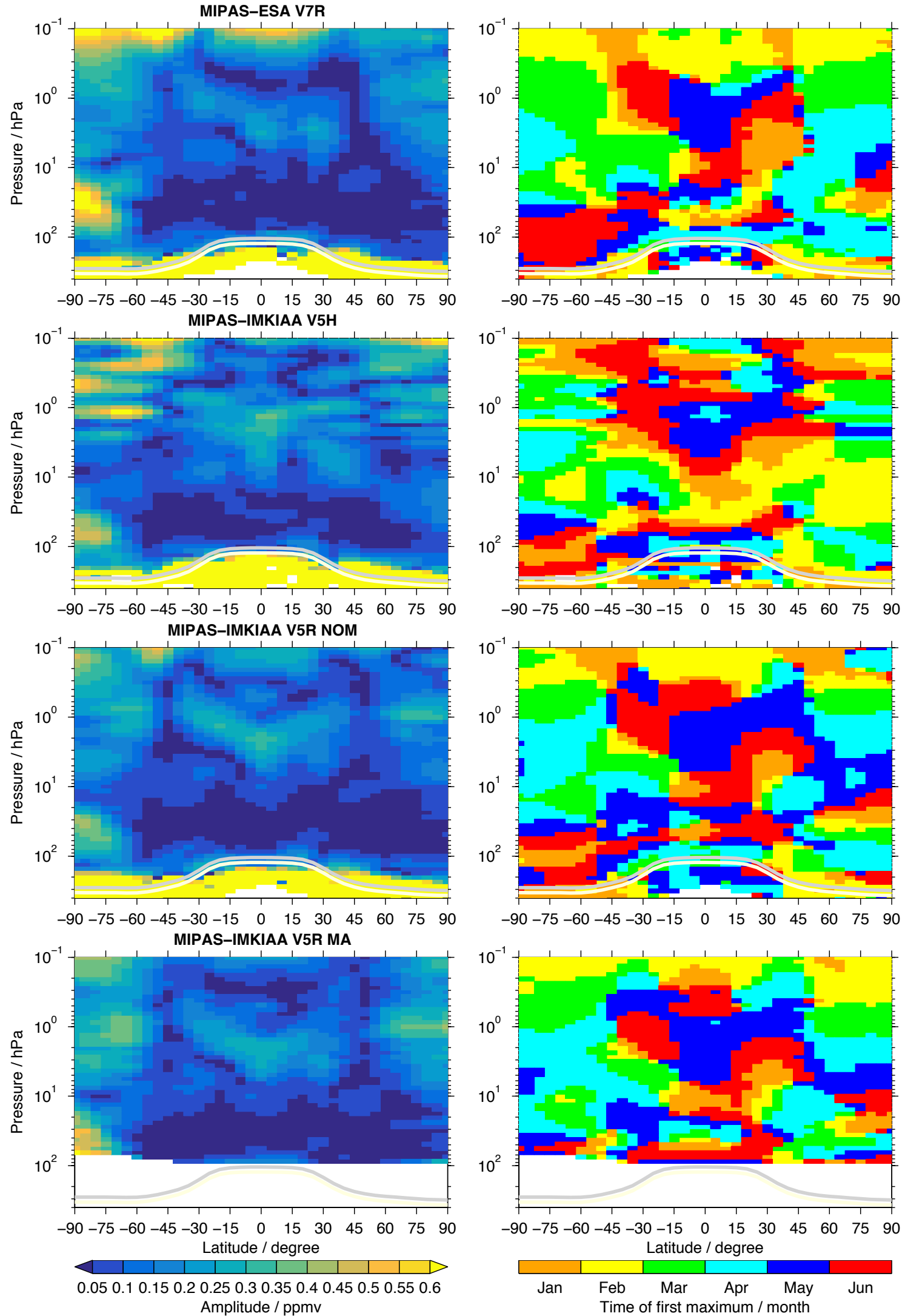

Continued on next page 

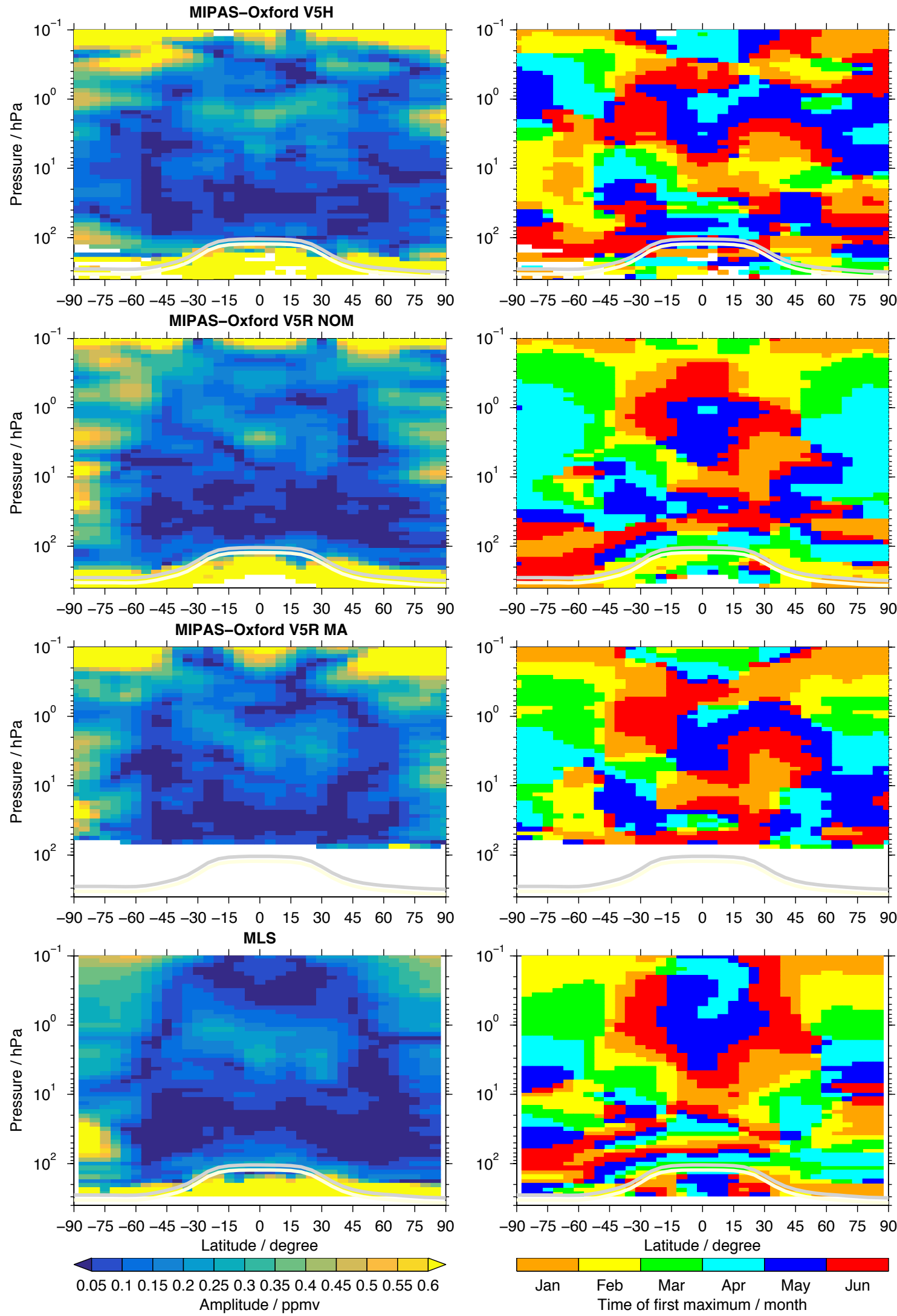

Continued on next page 

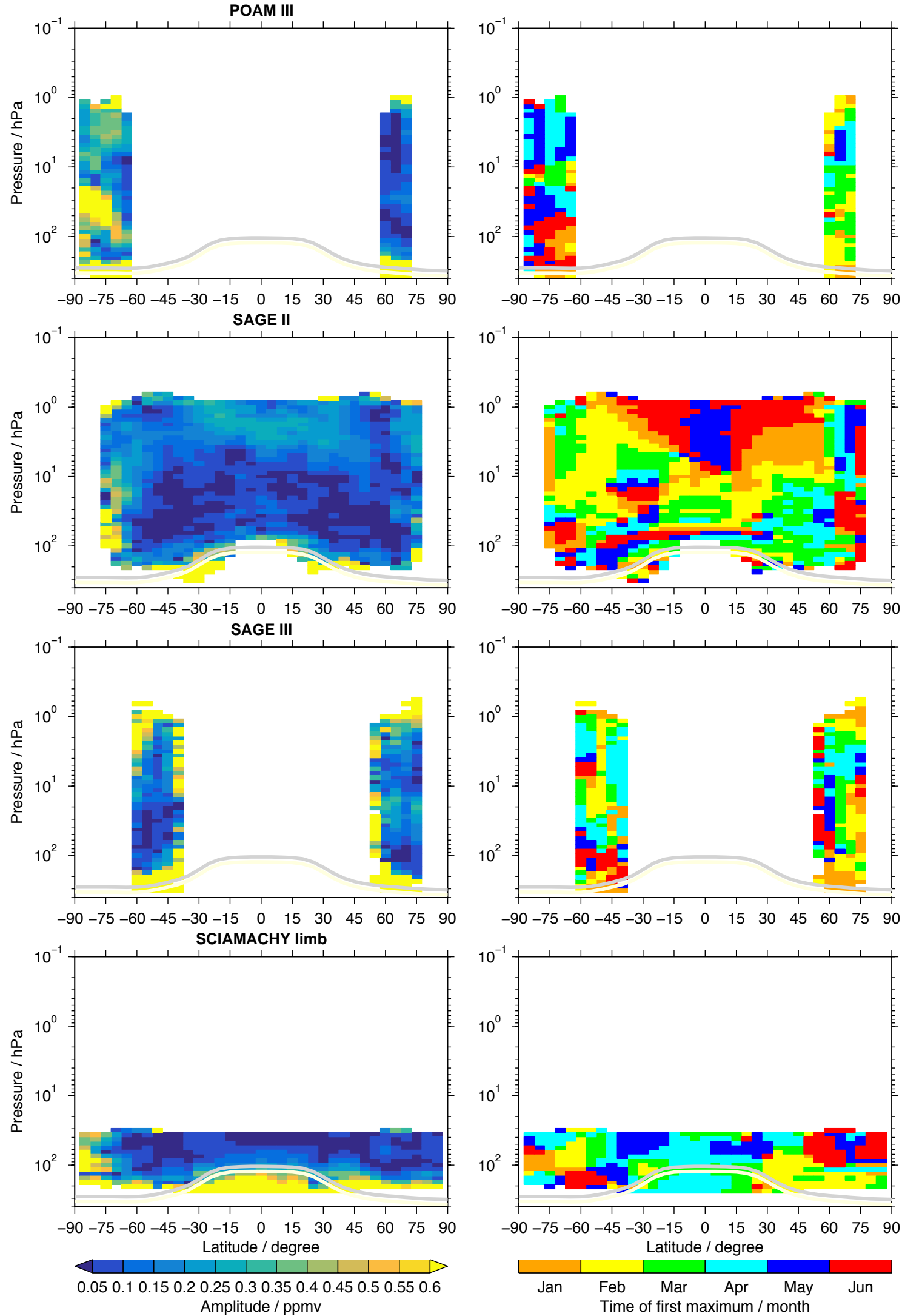

Continued on next page 

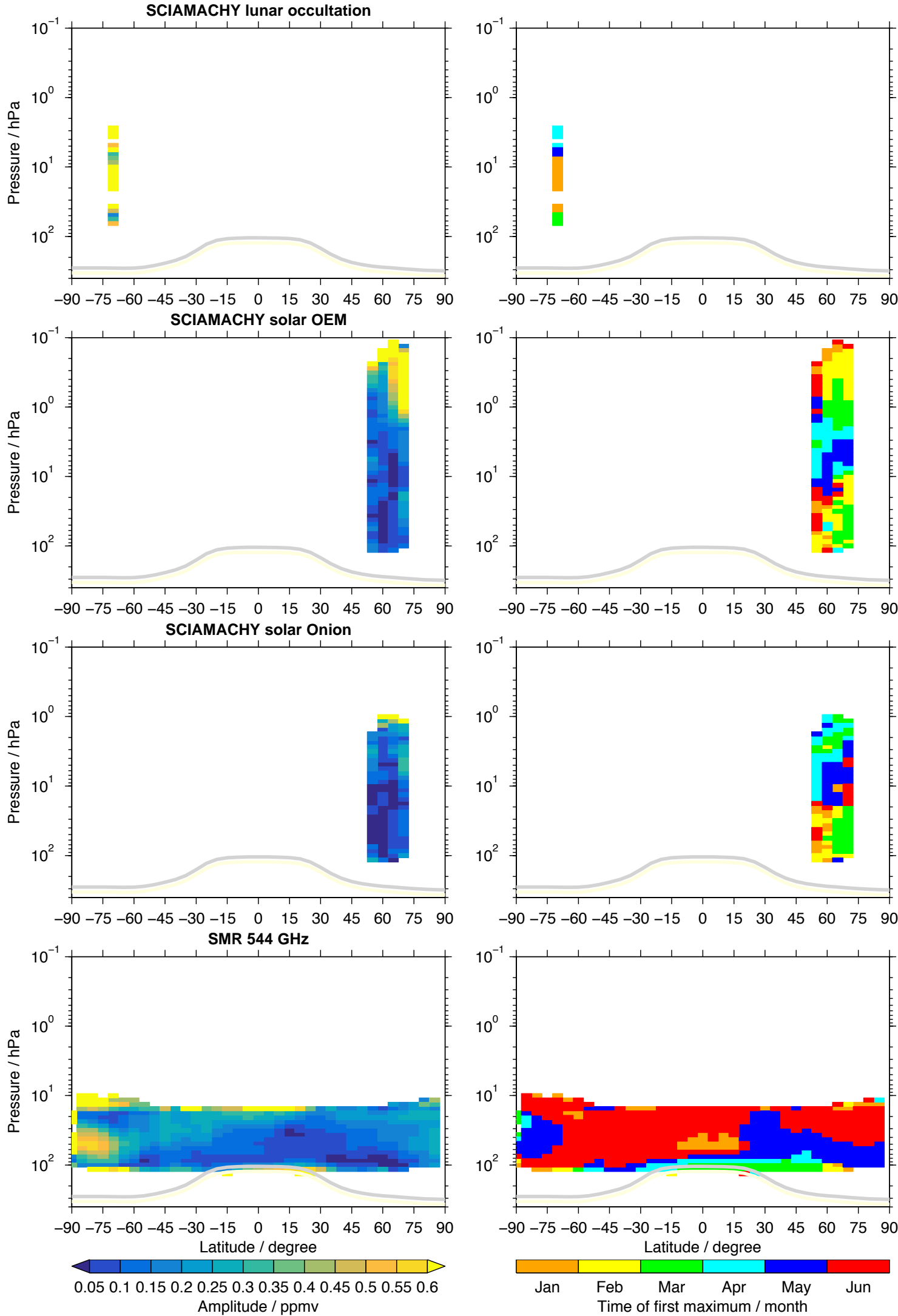

Continued on next page 

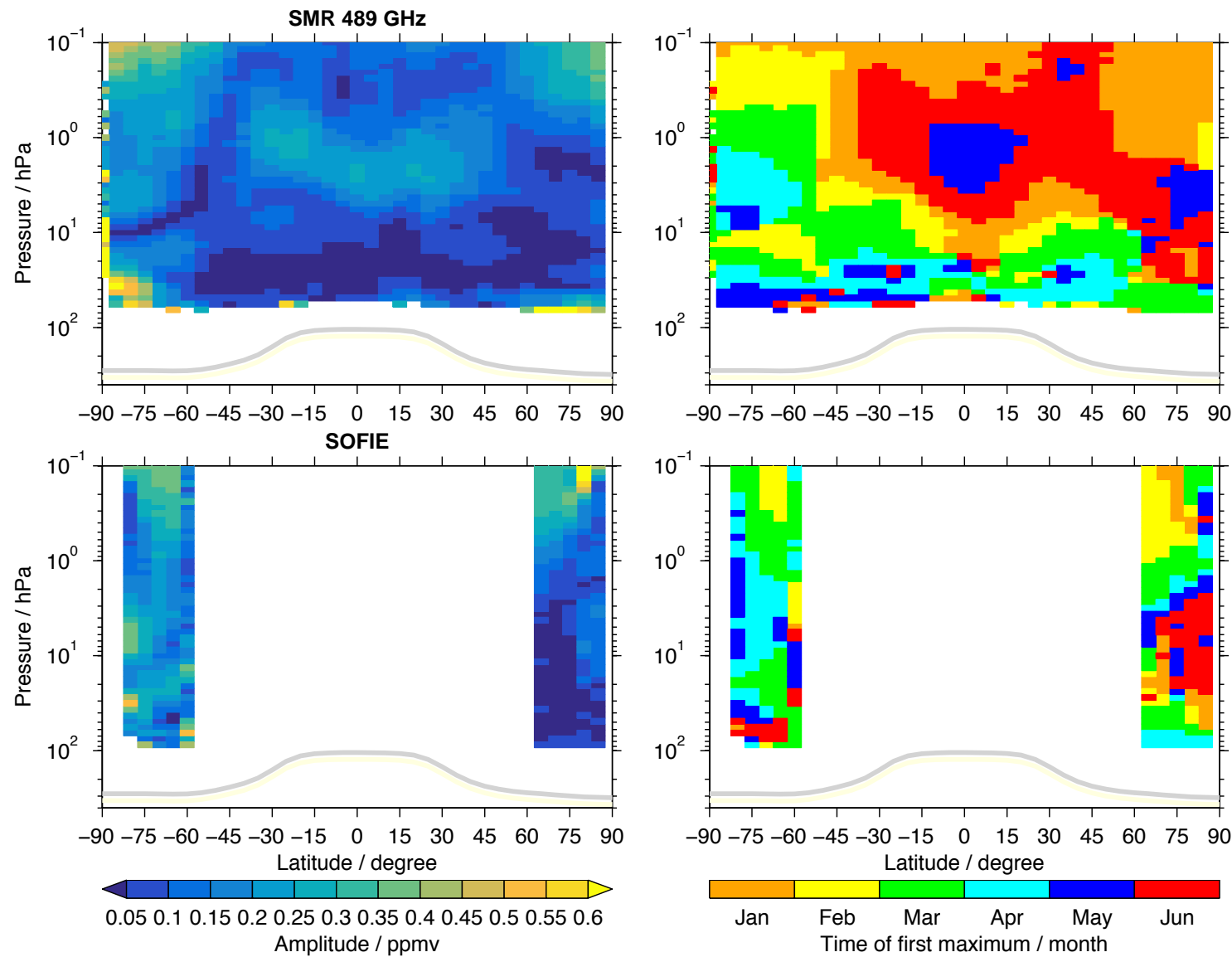

Figure 2: Latitude-pressure cross-section of amplitude (left panels) and phase (right panels) of the semi-annual variation in water vapour for the different satellite data sets. The phase represents the month of a calendar year where the first water vapour maximum is found in the semi-annual regression fit. The light grey and white line indicates the mean tropopause $(2000-2014)$ as derived from MERRA. Note that the amplitude scale is different than in Fig. 1. 

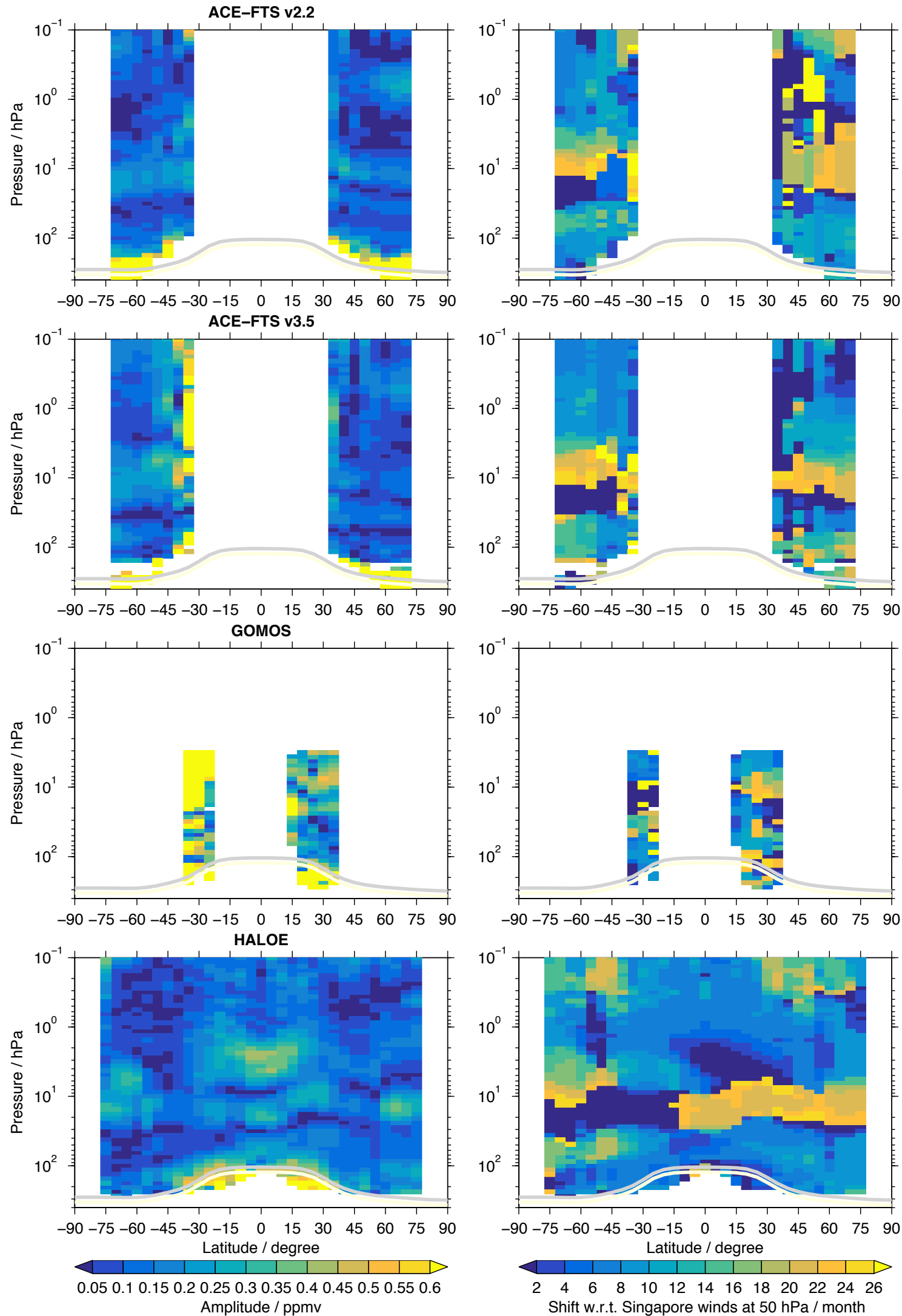

Continued on next page 

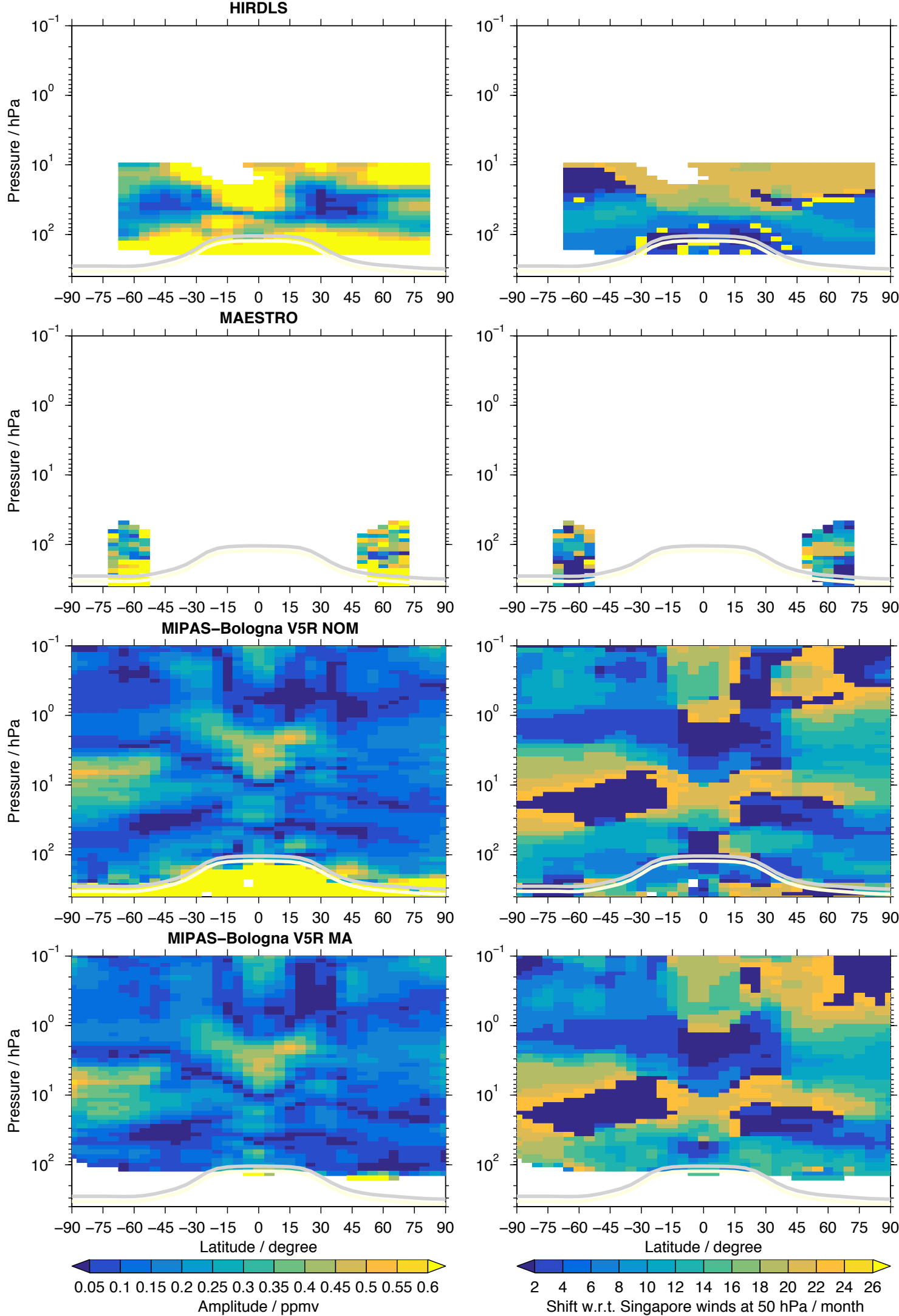

Continued on next page 

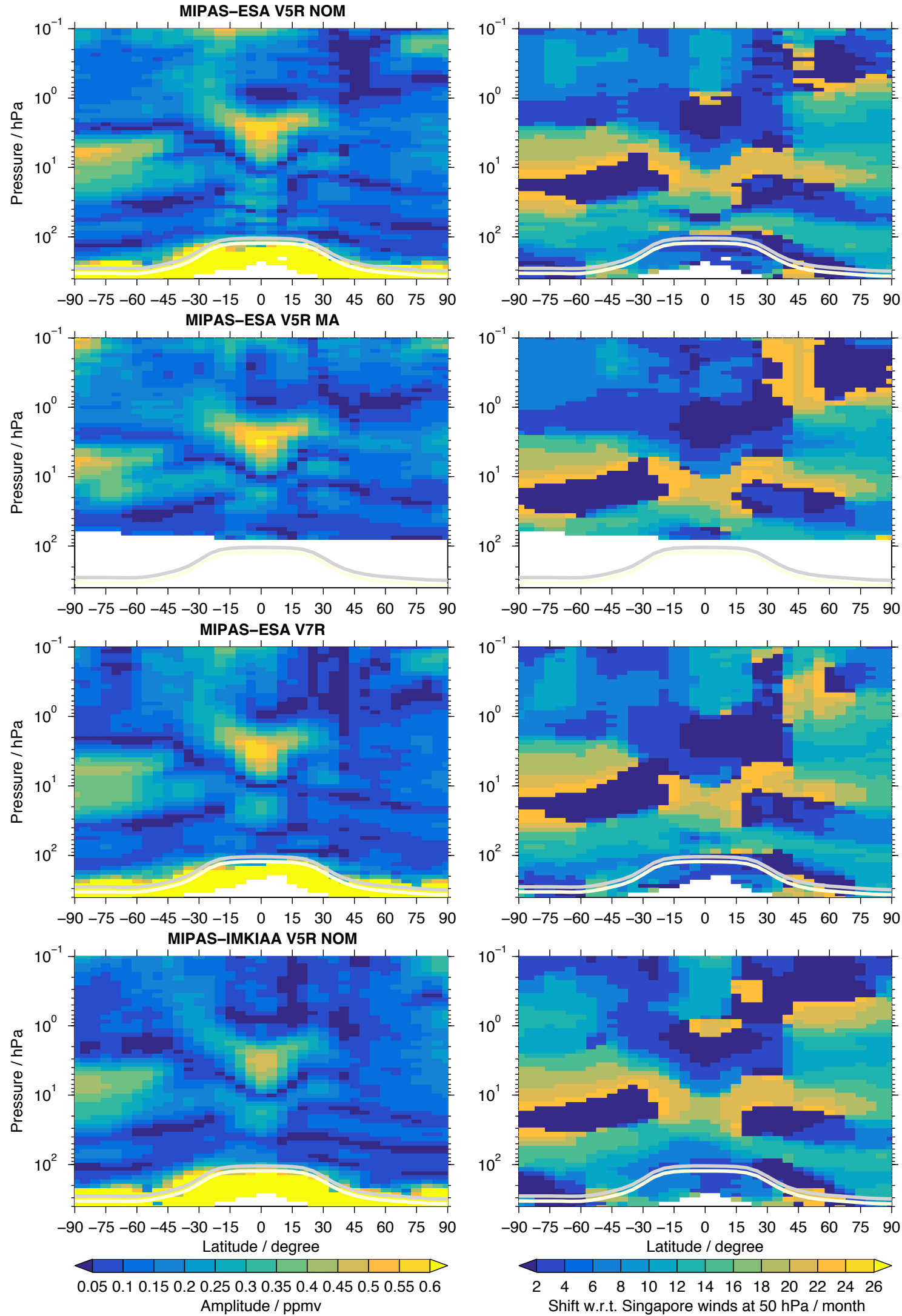

Continued on next page 

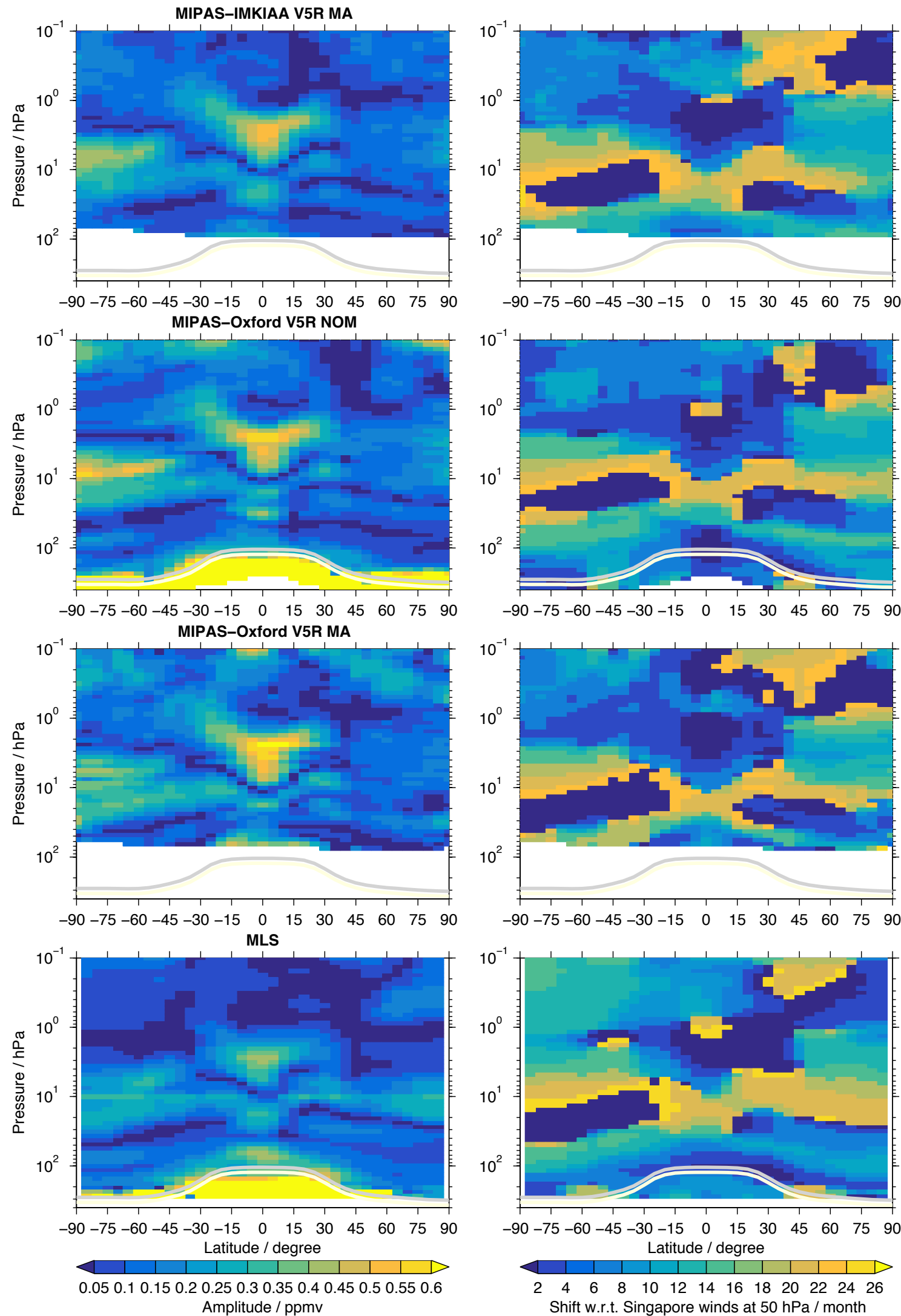

Continued on next page 

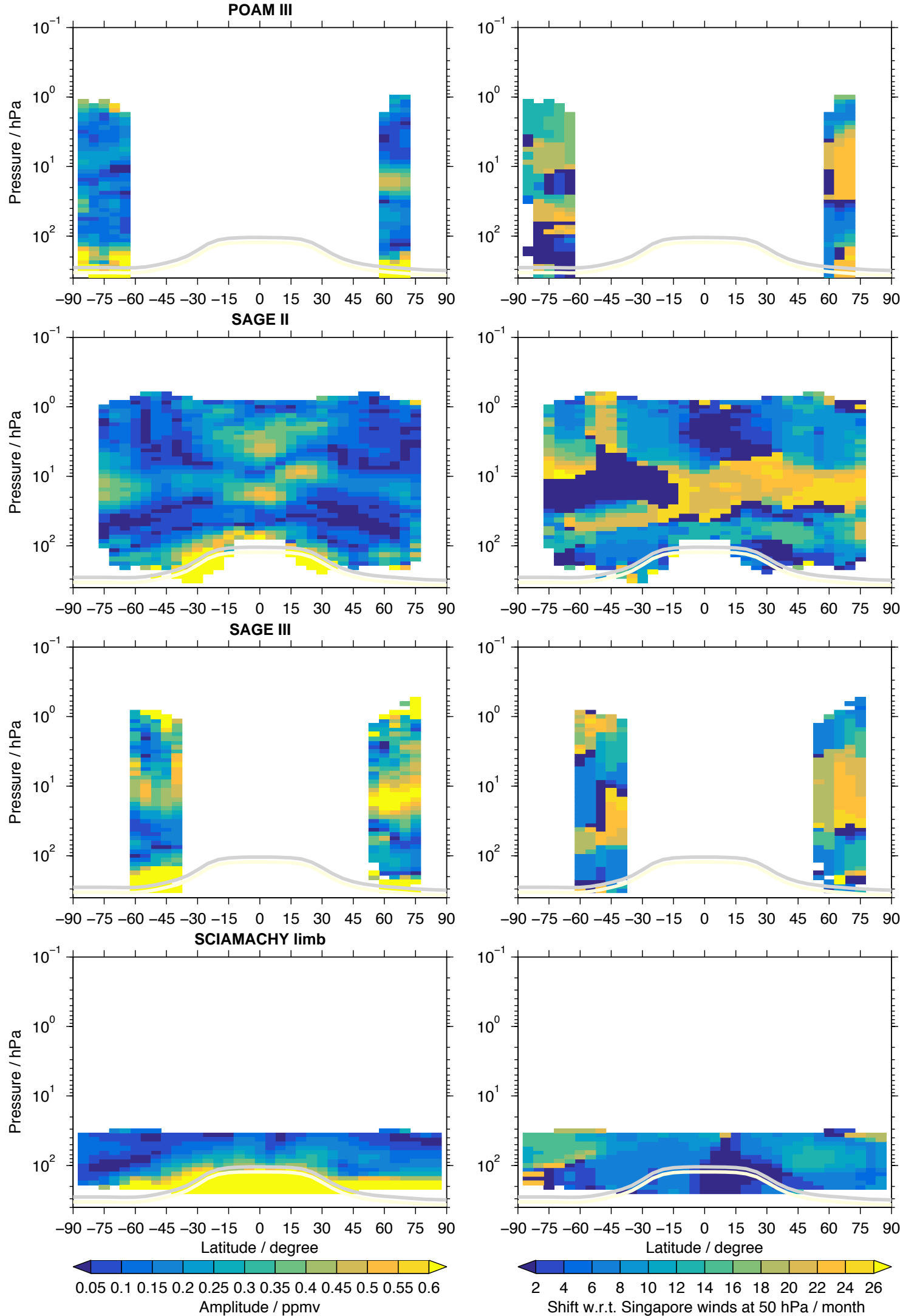

Continued on next page 

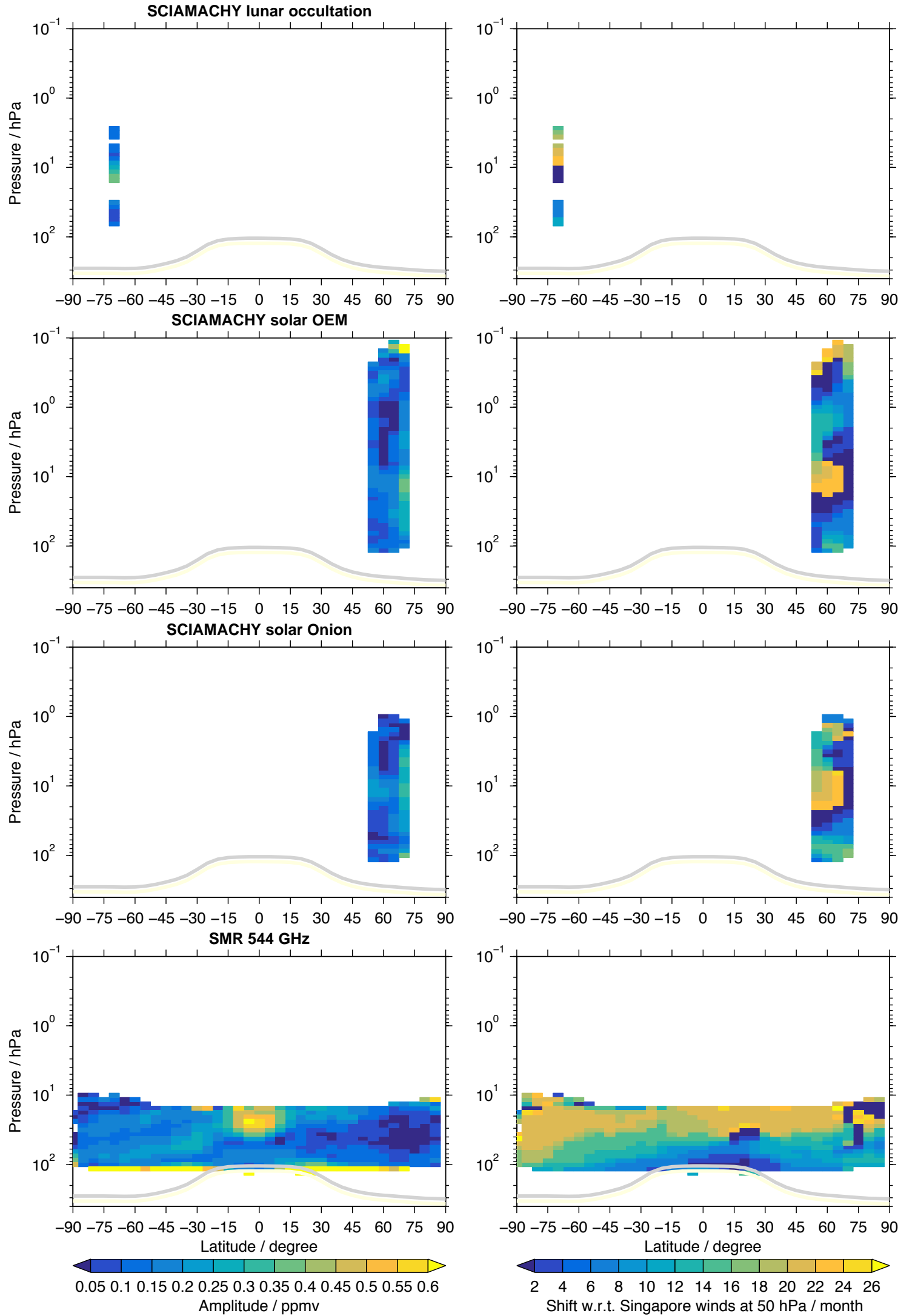

Continued on next page 

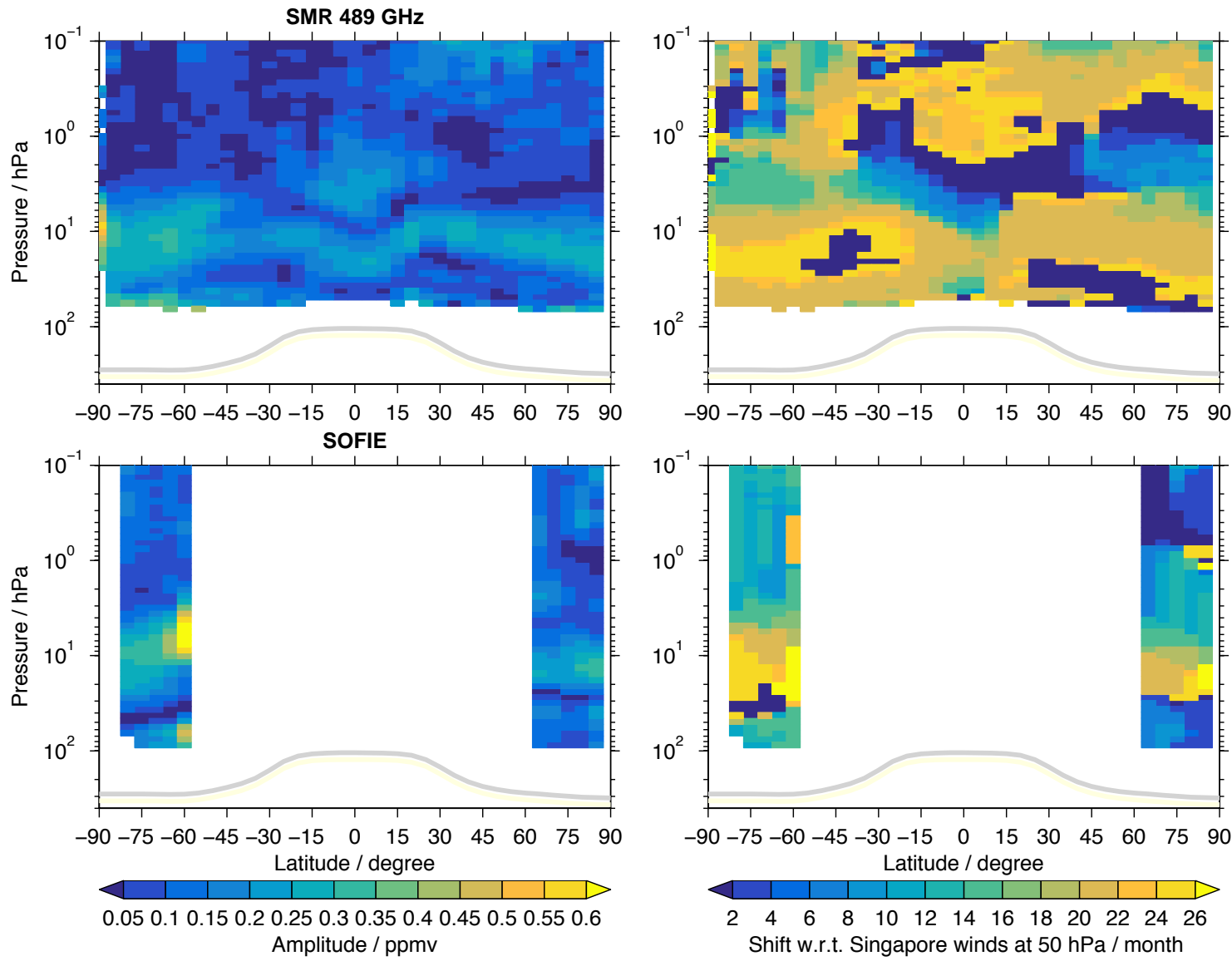

Figure 3: Amplitude (left panels) and phase (right panels) of the quasi-biennial variation in water vapour. The phase is defined as the shift of the QBO regression fit for which the correlation with the Singapore $\left(1^{\circ} \mathrm{N}, 104^{\circ} \mathrm{E}\right)$ winds at $50 \mathrm{hPa}$ maximises. 